\title{
Desvelando o isolamento social no cotidiano vivido na pandemia da COVID-19
}

\author{
Unveiling social isolation in the daily life of the COVID-19 pandemic \\ Revelando el aislamiento social en la vida diária de la pandemia da COVID-19
}

Recebido: 22/03/2021 | Revisado: 27/03/2021 | Aceito: 05/04/2021 | Publicado: 06/04/2021

\author{
Maria de Nazareth Rodrigues Malcher de Oliveira Silva \\ ORCID: https://orcid.org/0000-0003-4405-7378 \\ Faculdade Ceilândia, Brasil \\ Universidade de Brasília, Brasil \\ E-mail: malchersilva@unb.br \\ Adelma do Socorro Gonçalves Pimentel \\ ORCID: https://orcid.org/0000-0003-0048-4976 \\ Universidade Federal do Pará, Brasil \\ E-mail: pimenteladelma@gmail.com
}

\begin{abstract}
Resumo
A COVID 19 é uma pandemia de repercussão grave na saúde da população mundial, com comprometimentos no campo psicossocial da população. O objetivo do estudo é desvelar a vivência do isolamento social na pandemia da COVID 19. Para isso, realizou estudo de descritiva mista, quantitativa e qualitativa, com base a inspiração fenomenológica hermenêutica da linguagem, em ambiente virtual, com 231 voluntários, por meio do preenchimento de formulário on-line sobre a percepção do cotidiano na pandemia da COVID 19. Os dados das questões fechadas foram analisados por frequência numérica, enquanto as questões abertas com base a inspiração fenomenológica hermenêutica da linguagem. Os resultados mostram a descrição geral dos participantes e aprendizagens sobre a COVID 19; das emoções e comportamentos advindos da vivência na pandemia; e dos núcleos temáticos comuns sobre sua vivência no isolamento social, com produção de sentidos. Os colaboradores tratam a pandemia da COVID 19 e o isolamento social como um processo necessário e importante, mas não desejável, com conteúdos da linguagem não verbal associado a processos punitivos, consequências de atitudes ruins, de uma pratica comum interpessoal já vivenciada, qual seja a individualidade e afastamento da intersubjetividade, considerado processo comum da atualidade.
\end{abstract}

Palavras-chave: Isolamento; Sofrimento; Coronavirus; COVID 19.

\begin{abstract}
COVID 19 is a pandemic with a serious impact on the health of the world population, with impairments in the psychosocial field of the population. The objective of the study is to unveil the experience of social isolation in the COVID 19 pandemic. For this, it carried out a mixed, quantitative and qualitative descriptive study, based on the hermeneutical phenomenological inspiration of language, in a virtual environment, with 231 volunteers, through the filling in an online form about the perception of everyday life in the COVID 19 pandemic. The data from the closed questions were analyzed by numerical frequency, while the open questions based on the hermeneutical phenomenological inspiration of language. The results show the general description of the participants and learning about COVID 19; the emotions and behaviors arising from the experience in the pandemic; and the common thematic nuclei about their experience in social isolation, with the production of meanings. Employees treat the COVID 19 pandemic and social isolation as a necessary and important, but not desirable process, with non-verbal language content associated with punitive processes, consequences of bad attitudes, of a common interpersonal practice already experienced, whatever the individuality and distance from intersubjectivity, considered a common process today.
\end{abstract}

Keywords: Isolation; Suffering; Coronavirus; COVID 19.

\section{Resumen}

COVID 19 es una pandemia con un grave impacto en la salud de la población mundial, con deficiencias en el campo psicosocial de la población. El objetivo del estudio es dar a conocer la experiencia de aislamiento social en la pandemia de COVID 19. Para ello, se realizó un estudio descriptivo mixto, cuantitativo y cualitativo, basado en la inspiración fenomenológica hermenéutica del lenguaje, en un entorno virtual, con 231 voluntarios, mediante la cumplimentación de un formulario online sobre la percepción de la vida cotidiana en la pandemia COVID 19. Los datos de las preguntas cerradas se analizaron por frecuencia numérica, mientras que las preguntas abiertas se basaron en la inspiración fenomenológica hermenéutica del lenguaje. Los resultados muestran la descripción general de los participantes y el aprendizaje sobre COVID 19; las emociones y comportamientos que surgen de la experiencia de la pandemia; y los núcleos temáticos comunes sobre su vivencia en el aislamiento social, con la producción de significados. Los empleados tratan la pandemia de COVID 19 y el aislamiento social como un proceso necesario e importante, pero no deseable, con contenido 
de lenguaje no verbal asociado a procesos punitivos, consecuencias de malas actitudes, de una práctica interpersonal común ya experimentada, cualquiera que sea la individualidad y distancia de intersubjetividad, considerada un proceso común en la actualidad.

Palabras clave: Aislamiento; Sufrimiento; Coronavirus; COVID 19.

\section{Introdução}

A Covid-19 é uma pandemia de repercussão grave na saúde da população mundial, que interferiu na rotina cotidiana de todos, impondo a necessidade em seguir orientações sanitárias para prevenção da infecção, de modo a evitar comprometimentos no campo psicossocial, como também a saúde mental da população.

A pandemia da COVID 19 iniciou no final de 2019, na China e de forma avassaladora chegou nos continentes. O registro do primeiro caso no Brasil ocorreu em janeiro de 2020. Sua disseminação apresenta características peculiares: ocorre por via respiratória interpessoal, com sintomas que podem aparecer de dois a 14 dias após exposição, com pico entre cinco a sete dias após o contato; com diferença de infectados entre homens (2,8\%) e mulheres $(1,7 \%)$; evoluindo de uma síndrome gripal até insuficiência respiratória e agravamentos diversos e específicos associados a fatores externos (idade, condições de saúde, obesidade, comorbidade, entre outros); dividida por classificação quanto ao quadro clinico, como leve, moderada, graves e críticos; e com consequências diversificadas físicas, neurológicas, psiquiátricas, chegando ao óbito (World Health Organization [WHO], 2020).

No Brasil, o governo federal por meio do Ministério da Saúde (2020a) instituiu o Plano Nacional de Resposta às Emergências em Saúde Pública e criou Centros de Operações de Emergências em Saúde Pública para o novo Coronavírus $(\mathrm{COE} / \mathrm{nCoV})$. Além deste, em todos os Estados foram organizados comitês de enfrentamento a pandemia alinhados ao plano nacional de acompanhamento e notificação conforme a realidade e demandas locais.

As medidas gerais de controle da COVID 19 foram, portanto, relacionadas a auto higiene, etiqueta respiratória ao tossir e/ou espirar e distanciamento social de indivíduos no mínimo de um metro, e preferencialmente realização de isolamento social, possibilitando evitar o contato com pessoas e locais, e assim intervir no fator de transmissibilidade (WHO, 2019, 2020).

Mapear os efeitos da pandemia na população tem sido um permanente repto de gestão em função do desconhecimento dos desdobramentos do Corona vírus e sua instabilidade nas regiões do Brasil, entre manutenção, alta e estabilidade, além do comportamento negacionista da sociedade, que ainda insistem no não cumprimento das regras sanitárias, como por exemplo, no isolamento social. Neste cenário, os indicadores epidemiológicos atuais mudam diariamente, e que na oportunidade deste estudo registraram nove milhões e meio de infectados, dos quais, oito milhões foram recuperados, e 231.534 óbitos (https://www.esri.com/pt-br/covid-19/community-maps/gallery\#/).

É importante destacar que, apesar do crescente esforço da indústria farmacêutica e das instituições de pesquisa para produção de vacinas imunizantes contra a COVID 19 ainda há um longo caminho a percorrer para o controle da pandemia na população mundial. Além disso, são necessárias políticas públicas dos governos e da Organização Mundial de Saúde para o acesso das populações mais pobres a imunização e para contextos outros associados as situações decorrentes de uma pandemia.

Sobre impactos na saúde mental das pessoas, Pimentel e Silva (2020) ponderam sobre o cenário de incertezas e desafios propiciado pela pandemia da COVID 19, que se potencializa pelo estimulo excessivo dos noticiários e inúmeras Fake News. Alguns efeitos deste panorama é a intensificação das emoções com o temor de ser acometido pela doença, desenvolver sequelas ou mesmo vir a óbito, criando nesta conjuntura novos significados, valores e hábitos para o cotidiano da vida das pessoas.

Considera-se o cotidiano das pessoas por uma rede dinâmica de tarefas, ocupações e rotinas ao longo de um dia, influenciados de fatores psíquicos, sociais e culturais, que se moldam nos papeis ocupacionais e na biografia de cada um (Silva, 2020), onde a vivência se mostra pra cada um (Salles \& Matsukura, 2015). No cenário atual de pandemia da COVID 19 e isolamento 
social, diversos estudos da literatura (Pereira Et al, 2020; Lima, 2020; Guinancio et al, 2020) evidenciam um novo sentido ao mundo da vida de cada um, tornando geradores de significados que agenciam comportamentos e emoções diversas.

Este estudo baseia-se, portanto, em desvelar a vivência do isolamento social na pandemia da COVID 19, como uma realidade mundial, mas também singular e subjetiva, tendo como fundamento as ciências humanas, inspirada pela fenomenologia e hermenêutica da linguagem (Ricoeur, 1988).

\section{Metodologia}

Este estudo é originário do projeto de pesquisa de campo intitulado Expressão cotidiana e sofrimento psíquico na rotina originária da COVID 19, em consonância com às exigências das Resoluções CNS 466/2012, 510/2016, com aprovado pelo CONEP sob o número 4.032.234, que teve como objetivo conhecer as percepções sobre o cotidiano e a saúde emocional de mulheres e homens na vivência da pandemia da COVID 19 e discorrer sobre contexto da saúde mental na experiência de processos pandêmicos.

Trata-se de um estudo empírico de abordagem descritiva mista, utilizando análise quantitativa e qualitativa de estratégia fenomenológica, de base a inspiração fenomenológica hermenêutica da linguagem (Ricoeur, 1975), tendo como cenário o ambiente virtual, por meio da participação de voluntários no preenchimento de formulário on-line da sua perceção sobre o seu cotidiano frente a pandemia da COVID 19 e os processos sanitários de orientação a população.

Os colaboradores foram convidados por meio de chamada pública em rede social e deveriam apresentar como perfil para participação: homens e mulheres; maiores de 18 anos; de qualquer nível de formação e atividade; que confirmassem participação voluntaria por meio da assinatura do Termo de Consentimento Livre e Esclarecido (TCLE), e com a ciência dos procedimentos de garantia ao sigilo e autonomia. A coleta ocorreu no período de junho a dezembro de 2020, com 231 voluntários, na qual serão apresentados neste estudo algumas narrativas utilizando pseudônimos de colaboradores, em consonância aos preceitos ética dos estudos com serres humanos.

O formulário foi organizado no Google docs, com dois tipos de questões: (1) fechadas, sobre dados sociodemográficos, conhecimento sobre autocuidado preventivo para o contágio da COVID 19; emoções e comportamentos vivenciados neste período; e (2) abertas, sobre a descrição das percepções sobre a pandemia e o isolamento social.

Os dados das questões fechadas foram organizados e analisados descritivamente por frequência numérica, enquanto as questões abertas foram analisadas com base a inspiração fenomenológica hermenêutica da linguagem, que permite identificar estruturas significativas da experiência, e assim, desvelar modos de produção de sentidos, por meio dos atos e funções da fala (Ricoeur, 1975; Spínola, 2015).

\section{Resultados e Discussão}

Preparamos os resultados em três categorias: a) descrição geral dos participantes e aprendizagens sobre a COVID 19; (b) descrição das emoções e comportamentos advindos da vivência na pandemia; e c) núcleos temáticos comuns sobre sua vivência no isolamento social, com destaque as narrativas ilustrativas de produção de sentidos.

Dos 231 colaboradores do estudo temos representantes das regiões do Brasil e um de Portugal. Destes, 189 são do centro oeste (81,1\%); 24 (10,3\%) da região Norte, 09 (3,8\%) do Sudeste, 05 (2,1\%) do Nordeste, e 04 (1,7\%) da Sul.

As características sócio demográficas dos colaboradores do estudo foram organizadas na Tabela 1. 
Tabela 1 - Dados sociodemográficos dos participantes do estudo.

\begin{tabular}{llc}
\hline Conteúdo & Características & N: 231 (100\%) \\
\hline Sexo & Feminino & $182(78,8)$ \\
Idade (anos) & Masculino & $49(21,2)$ \\
\cline { 2 - 3 } & 18 a 29 & $122(52,8)$ \\
& 30 a 49 & $74(32)$ \\
Escolaridade & 50 a 60 & $26(11,3)$ \\
& Acima de 60 & $09(3,9)$ \\
\cline { 2 - 3 } & Ensino superior & $125(54,1)$ \\
& Pós-graduação & $75(32,5)$ \\
Atividade laborativa atual & Ensino médio & $21(9,1)$ \\
& Curso técnico & $06(2,6)$ \\
& Ensino Fundamental & $04(1,7)$ \\
\cline { 2 - 3 } & Desemprego & $91(39,4)$ \\
& Serviço público & $79(34,2)$ \\
& Em empresa privada & $62(26,8)$ \\
& Outros & $12(3,8)$ \\
\hline
\end{tabular}

Fonte: Pesquisa (2020).

As prevalências dos dados sociodemográficos foram de mulheres (78,8\%), com idades entre 18 a 29 anos (52,8\%), ensino superior completo ou incompleto $(54,1 \%)$, em profissões diversas da saúde, educação, humanas, do setor público e privado, sendo que destes, 32,5\% possuem ou estão cursando uma pós-graduação e no momento do estudo encontram-se desempregados (39,4\%).

Neste contexto, coincide com estudos da Fiocruz (2020) e Rosser et al (2021) que afirmam que a Pandemia repercutiu também impactos sociais, econômicos, culturais e históricos entre as histórias das pandemias, citando neste processo infectados e mortos competindo em escala significativas a sustentação econômica do sistema financeiro, o acessos a bens materiais, de subsistência, provocando nesta ordem, uma recessão econômica e o recrudescimento da pobreza na população.

Com relação a segunda categoria sobre a aprendizagem na COVID 19 os colaboradores destacaram a sobrecarga de informações dos meios de comunicação que recebem, de conteúdo confuso, jogo político entre as esferas governamentais com o governo federal e as fakenews. Esta realidade é comprovada pelas informações que são distribuídas mundialmente de forma instantânea nas redes sociais das pessoas. De acordo com o site Internet Live Starts, a cada segundo o mundo produz e compartilha na web em média 2,9 milhões de e-mails, 8.947 posts no Twitter, 987 fotos no Instagram, 4.602 chamadas no Skype e 82.386.82 386 pesquisas no Google, e visualizando este site observa-se que os números crescem (https://www.internetlivestats.com/).

Destacam entre as narrativas dos colaboradores, que: 23 colaboradores informaram que foram infectados pelo vírus e necessitaram de internação; 120 tiveram familiares próximos infectados, e destes 51 foram a óbito; e 189 buscaram continuamente orientações e notícias sobre a COVID 19, e onde 78 acreditam em todas as informações acessadas. Neste sentido, destaca-se relevante distinguir o acometimento biológico e o campo do cuidado junto a população com outros contextos, como o formato de comunicação e intervir nas fake news, portanto, acompanhar as dimensões nele envolvidas, com ações de integralidade de politicas intersetoriais (Pimentel \& Silva, 2020).

A Organização Panamericana de Saúde (2020) já classificava todo este cenário como uma infodemia, que significa um excesso de informações, algumas precisas e outras não, que tornam difícil encontrar fontes idôneas e orientações confiáveis quando se precisa (p. 2). O que significa que a pandemia concretizou uma dinâmica real atual, mas que nesta realidade se fortaleceu, com a multiplicação exponencial, num curto espaço de tempo de um evento específico, como a pandemia atual. Este aspecto desencadeia 
uma série de aspectos negativos, como: o descrédito pela ciência, mudança de comportamento, comportamento de risco, aumentando índice de transmissibilidade e comprometendo as ações de promoção de saúde.

Do total de colaboradores do estudo é significativo o quantitativo de pessoas que conseguem fazer isolamento ( $83,5 \%)$, podendo estar relacionada ao tipo de atividade laborativa desenvolvida no período do estudo, na qual prevaleceu pessoas desempregadas, autônomos, servidor público, donas de casa, entre outros, possibilitando o cumprimento das medidas de isolamento instituídas pelos planos estaduais de combate ao COVID 19, entendendo que fatores socioeconômicos, como necessidade de trabalho, inicialmente gerava o descumprimento. Entretanto, estudos da WHO (2020) citam também a negação e ansiedade como processos que influenciam o cumprimento do isolamento social. Além disso, noticiários mostram diariamente, que com o tempo vivido com a pandemia e consequente desgaste ao cumprimento do isolamento social as pessoas passaram a cada vez mais a flexibilizar esta estratégia de saúde, gerando consequentemente, como em Manaus, uma nova onda de contaminação (Madeiro, 2021).

Entretanto, a COVID 19 e as consequências advindas desta pandemia no campo da saúde física e das medidas pública sanitária foi enfoque principal de saúde pública, como o incentivo das pessoas para o isolamento social como principal estratégia preventiva primária para o combate a Pandemia, no sentido de minimizar os infectados e diminuir ações da lata complexidade em saúde. Entretanto, também ocasionou emoções e comportamentos vivenciado destacados pelos colaboradores do estudo (Figura 1).

Figura 1. Lista de emoções e comportamentos dos participantes vivenciado na pandemia e isolamento social.

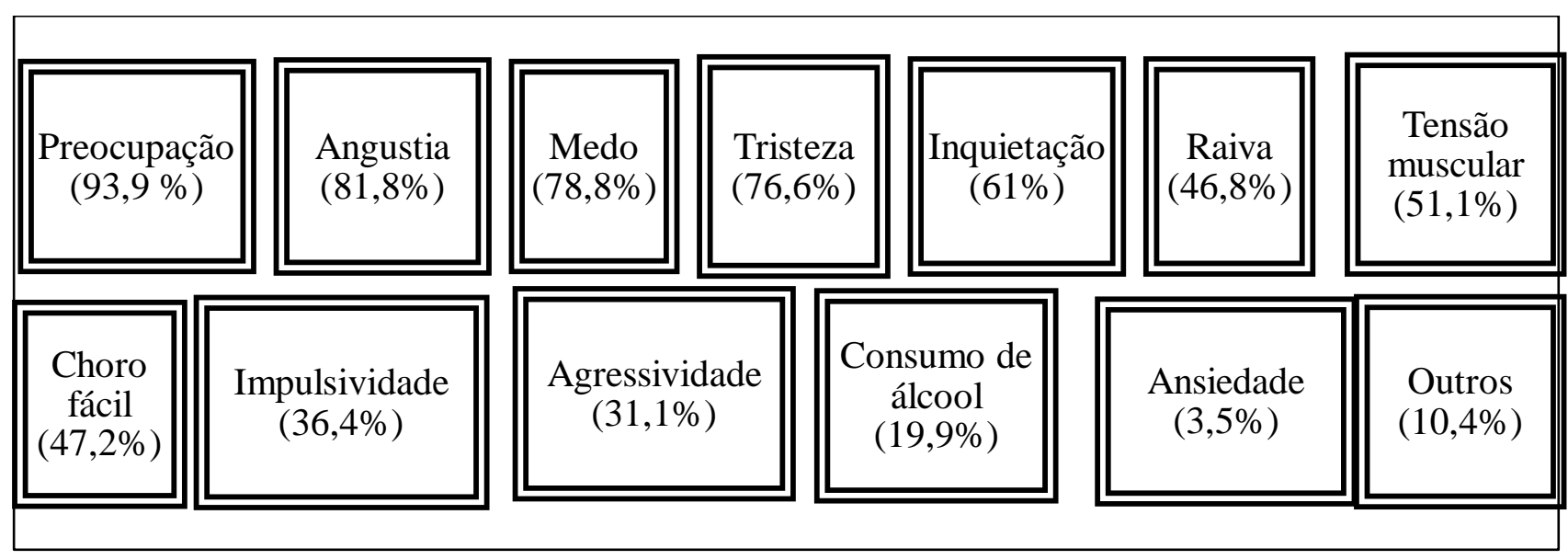

Fonte: Pesquisa (2020).

Estas emoções e comportamentos vivenciados pelos colaboradores mostram-se como destaques índices estatísticos extremos: da preocupação em 93,9\%, a angustia (81,8\%) e medo (78,8\%) até o consumo de álcool em 19,9\% e a ansiedade (3,5\%), ou mesmo outros comportamentos e emoções (10,4\%), como o bruxismo, medo de morte, receio de ficar sozinha, impotência, falta de concentração, tendência suicida, tédio profundo, piora no quadro psiquiátrico, descrença, insegurança, pânico de perder familiar, todos estes considerados pródromos de sofrimento psíquico. Estudos da literatura discorrem sobre a saúde mental da população na pandemia da COVID 19, concluindo que o medo do cenário intensifica os níveis de estresse e ansiedade em pessoas saudáveis e aumenta sintomas pré-existentes, amplificando o sofrimento psíquico na população e proporcionalmente questões de vulnerabilidades associadas, como violência doméstica, uso abusivo de álcool e outras drogas, entre outros (Pereira Et al, 2020; Lima, 2020; Guinancio et al, 2020).

Para as emoções e comportamentos destacados neste estudo, Pimentel e Silva (2020) associaram as emoções a flor da pele como sinônimo de uma diversidade de emoções advindas de todo o processo vivenciado com a COVID 19, desde da populaçnao 
em geral até profissionais da linha de frente, idosos, pessoas em vulnerabilidades, pessoas em condições de restrição de liberdade, estudantes, entre tantos outros. Estas autoras reforçam que o tempo de isolamento social elou processos outros estão vinculados a personalidade, e a subjetividade de cada um na relação com o mundo (p. 31), portanto, um processo singular nas dimensões de vida de cada um.

Os sentidos da linguagem dos colaboradores sobre as vivências na pandemia da COVID 19 e no isolamento social mostraram de forma ambivalente, evocados para o si mesmo e para o contexto coletivo social. O isolamento social foi considerado como:

uma ação fundamental, necessária, útil, de preservação, importante, consciente, o único remédio, que deve ser mantida, mas também considerada como muito ruim, difícil, desgastante, pior coisa do mundo, agonizante, assustador, preocupante, que afeta muito a saúde mental, de grande desestruturação psíquica (Colaboradores).

De forma ambivalente apresentaram também sentidos de fala como um período de tormenta, reflexão e valorização da vida, associando este momento como significado de um comportamento coletivo e uma ação público governamental, como: que falta seriedade e compromisso negligenciados (Colaboradores).

Acredito que a pandemia da Covid-19 piorou, de modo geral e no mundo inteiro, aspectos que já eram ruins. Quem se encontrava em situação de vulnerabilidade financeira antes da pandemia teve sua situação piorada por ser impossibilitado de trabalhar ou por demissões. Quem já tinha problemas emocionais também teve piora no quadro por não poder fazer atividades simples do dia a dia, como visitar um amigo para se distrair ou dar uma volta para espairecer (Colaboradores).

A terceira categoria dos núcleos temáticos comuns da vivência no isolamento social apresentou unidades de significação da função da linguagem de duas formas: (1) a pandemia e o isolamento social afetando a si mesmo; e (2) a pandemia e o isolamento social nos processos coletivos sociais.

\subsection{A pandemia e o isolamento social afetando a si mesmo}

Os colaboradores tratam a pandemia da COVID 19 e o isolamento social como um processo necessário e importante, mas não desejável, com conteúdos da linguagem não verbal associado a processos punitivos, consequências de atitudes ruins, de uma prática comum interpessoal já vivenciada, qual seja a individualidade e afastamento da intersubjetividade, considerado processo comum da atualidade.

Cansativo, mas o isolamento é necessário, para aqueles(as) que podem fazê-lo. Em mim, gerou e continua gerando desânimo, desconforto, dificuldade nos estudos, baixa autoestima, tristeza, ansiedade, baixa produtividade e afastado de inúmeras pessoas e ciclos de redes de amizades que convivia, uma espécie de isolamento emocional também. Estudo EAD, trabalho remoto e relações virtuais estão me levando a tristeza, momentos de altos ou muito baixos níveis de produtividade, dificuldade em conversar, sensação de ser pouco suficiente e vontade de isolar o emocional. Porém, sei que é importante continuar em isolamento social (Colaborador). 
É necessário, porém dolorido ver algumas pessoas perderem tudo financeiramente, ver pessoas conhecidas faleceram por conta do vírus e a família não poder se despedir, sair da sua rotina e começar uma nova totalmente diferente e cheia de regras. Mais difícil ainda ver como algumas pessoas não tem empatia umas pelas outras (Colaborador).

Portanto a vivência do isolamento social na pandemia da COVID 19 foi de compreensão das regras, consideradas necessárias, mas não desejáveis que, a despeito de ser uma promoção em saúde, promove também danos a saúde, autorreflexão de processos existenciais de si mesmo, de finitude e vida, e de processos espirituais.

Mas a questão do isolamento social me fez pensar sobre aquelas pessoas que, por motivos diversos, já se encontravam isoladas antes mesmo da pandemia e como isso é problemático sendo que somos seres que precisam de socialização para viver (Colaborador).

Período de tormenta, reflexão e valorização da vida; preocupação exacerbada aos meus avós e pessoas queridas de grupo de risco, aumento do amadurecimento humano, desgaste físico e emocional. Irritabilidade, choro intenso, Ansiedade e crise depressiva, sofrimento por antecedência. Pensamento voltado para o pior, de perda repentina dos entes queridos, sem a garantia da dignidade de no mínimo um sepultamento presencial. Gastos financeiros importantes, receio de não haver leito de UTI. Impotência. Revolta com pessoas que não respeitavam a quarentena nem as normas de segurança, as medidas preventivas. Muita dor e sofrimento. Minha rua inteira teve casos de contaminação, vizinhos faleceram. Foi um período terrível, mas de grande amadurecimento para a vida (Colaborador).

Momento que nos pegou de surpresa afetando diretamente todas as nossas atividades cotidianas, impactando diretamente nas nossa rotina e ocupação. Mas, também de nos permitir refletir sobre projetos esquecidos, descobrir outras habilidades, se aproximar mais do divino, é o que tenho feito para me manter em equilíbrio (Colaborador).

Lamentável a situação atual, digo levando em consideração todas as situações vivenciadas, todo o impacto causado, saúde, econômica, política, os desempregos... Eu mesmo me apego a minha fé em Deus, pois somente Ele tem dado força para seguimos (Colaborador).

Estar dentro de casa durante todo esse tempo, sem poder sair e esfriar a cabeça como antes era possível, faz com que um turbilhão de sentimentos venha à tona. Passei a ter pensamentos que antes não eram comuns, passei a sentir coisas que antes não sentia com frequência. Estou muito mais emotiva e sensível. Isso somado à angústia de tantas pessoas enfrentando essa pandemia, o medo de alguém que amo se infectar e resultar no pior e a negligência governamental pioram tudo o que citei inicialmente (Colaborador).

Entende-se com as narrativas alguns significados, como, processo de luta e fuga, ou seja, sentido sobre a gravidade e a relevância do cuidado de si mesmo, com o cumprimento das regras sanitárias e empatia em relação as necessidades dos outros, com base aos noticiários instantâneos advindos dos meios de comunicação e recursos tecnológicos; ao mesmo tempo, comportamento de negação, de descredito e credibilidade sobre a realidade vivida. 


\subsection{A pandemia e o isolamento social nos processos coletivos sociais}

O sentido da linguagem apresentou uma segunda unidade desvelado nas narrativas dos colaboradores sobre a vivência na pandemia e no isolamento social repercutindo nos processos coletivos sociais, onde observou que a medida que se afastavam das atividades de grupalidade instituída pelo isolamento social aumentou a observação e acompanhamento da vivência na coletividade social.

A Pandemia veio como um muro que caiu de repente na frente de nossa pressa e a colisão provocada nos desnorteou completamente. Presos dentro de casa, para quem realmente se comprometeu a manter a si e aos seus próximos seguros, nos vimos presos não só com nossos parentes, mas também com as coisas que mais odiávamos em nós mesmos. Quando não havia quarentena, o cotidiano ainda era suficiente para nos distrair do nosso íntimo, já o isolamento nos botou frente a frente com nossos medos e inseguranças. O isolamento social foi necessário para que vidas não fossem perdidas e para que fosse vista a necessidade de mais contato e compartilhamento entre nós, seres sociais (Colaborador).

Para os colaboradores a COVID 19 e o isolamento social aflorou uma postura avaliativa da conduta entre as pessoas sobre as diversas formas que cada um interpreta e vive a realidade, aflorando como sujeitos críticos sobre as condutas de outros sujeitos, reverberando em temáticas nas narrativas sobre empatia, desrespeito, banalidade a vida, solidariedade, entre outros.

Trata-se de uma histeria desnecessária que causou mais prejuízo econômico... Fenômeno global do Planeta Terra que nos imputa reflexão ampliada sobre a vida também a morte (colaborador).

Uma vivência inédita para repensar comportamento individual e coletivo (Colaborador).

Esta conduta avaliativa foi desvelada pela linguagem com sentidos diversos, como:

(1) A diversidade na forma como cada pessoa vivência o isolamento social na pandemia com divergências na compreensão e cumprimento das novas regras sanitárias;

O isolamento social foi necessário para que o vírus não se espalhasse rapidamente e causasse um colapso nos hospitais, porém as pessoas por falta de informação, negligência ou acreditaram em fakenews não cumpriram o isolamento e todos nós pagamos a irresponsabilidade de uma parte (Colaborador).

(2) A equidade e acesso da população para o cumprimento das novas regras sanitária, como condições socioeconômicas para o isolamento social, com discussões sobre pobreza, grupos vulneráveis, políticas publicas com justiça, e o dever estatal e não específico de políticas governamentais no cuidado da população;

Genérico demais. Mas, minha opinião é que a pandemia exacerbou um quadro de doença social. A Desigualdade social. Enquanto não resolver isso, não haverá progresso real.

Deveria haver outro meio. Tem perguntas aqui sobre a Covid, óbitos, mas não tem sobre mortes por depressão, suicídio, e a causa é o isolamento, porque perdeu o emprego ou porque o pai de família fechou o estabelecimento ou simplesmente faliu. E sim, infelizmente eu conheço (Colaborador). 
(3) O acesso ilimitado a informação pelos meios de comunicação de forma maciça associado a jogos de comunicação de interesses particulares, com massificação das informações, sem observar as especificidades locorregionais do País;

No começo eu estava muito mais apreensiva com a situação. Agora acho que já me conformei, o que é um absurdo visto que ainda estamos em crise. Eu já fazia isolamento social de praticamente um ano antes da pandemia começar pois faço cursinho online, o que inviabiliza muito o contato com outras pessoas. O isolamento do ano anterior me possibilitou o autoconhecimento e aprendi a ficar apenas em minha companhia. Não foi um processo mais feliz da minha vida, mas os frutos foram (e ainda são) uma delícia! Já o isolamento desse ano, foi ainda mais difícil. Coisas muito perturbadoras aconteceram em minha vida e eu não tinha emocional nenhum para lidar com elas. Jurei que não conseguiria chegar aos 20 anos, mas consegui (surpresa!). Não estou consumindo notícias e muito menos as redes sociais atualmente porquê sinto que o excesso de informação está acabando com a minha sanidade mental enfraquecida. Eu torço para que tudo isso passe e que eu saia melhor e mais forte de toda essa situação.Cada dia que se passa, percebo que não possuo uma opinião formada sobre isso (Colaborador).

(4) O uso dos recursos públicos no enfrentamento da pandemia, com ausência de parcerias das políticas intersetoriais nas esferas do governo. No caso do Governo Federal o descrédito pela ciência e a valorização de condutas terapêuticas empíricas;

Mostrou o despreparo e a politização de uma situação grave, onde o Estado não soube conduzir o problema de maneira racional. Políticos e imprensa manipulam a opinião pública dividindo a população em dois lados quando o correto seria promover o debate especializado de pensamentos distintos para chegar a uma estratégia adequada e eficaz. Somos um povo nas mãos de loucos e homens sedentos por poder e dinheiro (Colaborador).

Despreparo! O sentimento que eu tenho no momento é de tristeza, de perda, de luto. Luto por todas vidas perdidas, por todos os sentimentos interrompidos e por todo despreparo do governo e da população; luto por todos que estão fazendo pouco caso da doença e da dor do outro. Tristeza de vê tantas vidas perdidas e que não puderam ter uma despedida digna (Colaborador).

Não vejo saída. A política cruel de extermínio da população me deixa sem esperança, sem perspectiva. Importante salientar que não acredito em tudo sobre COVID porque só busco me informar por reportagens sérias e veículos confiáveis, sempre tendo a ciência como premissa (Colaborador).

É de extrema importância que todos entendam o verdadeiro significado de isolamento social, e entendam que estamos passando sim, por uma pandemia nível mundial e que se fosse apenas uma "gripezinha" não teríamos perdido milhões de mães, pais, avós, filhos, amigos! (Colaborador).

A organização Mundial de Saúde (2019) já alertava que disparidades socioeconômicas decorrentes de perdas financeiras, falta de acesso ou mesmo barreiras sistêmicas agravam a saúde mental de uma população, gerando conflitos internos, na dinâmica das relações, como também externos sociais, e para isso, recomenda um acompanhamento digno de todos os indivíduos, desde de uma atenção de promoção a saúde, que ampare na regulação de diretrizes da informação e da integralidade de ações, até o acesso 
e cuidado digno de intervenção em saúde, sem estigma, mas lidando com ações em saúde mental na comunidade para lidar com o estresse psicológico.

Otu, Charles e Yaya (2020) reforçam nestes aspectos quesitos para lidar com os danos do isolamento social, como estilo de vidas ativos, acesso a uma alimentação saudável e ligações sociais em um número considerável de plataformas de comunicações e estabelecimentos de coalizões e redes comunitárias de suporte apoio, mas que infelizmente são desafios para grupos e locais no Brasil.

Pimentel e Silva (2020) em estudo teórico em documentos governamentais apresentou que a abordagem ainda se mostrava incipiente com relação aos danos psicossociais na pandemia, limitando-se a comportamento de higiene e isolamento social, lidar com as Fake News, entre outros, naturalizando sentimentos comuns da existência humana, geradores de sofrimento psíquico. Além disso, as autoras apontam para pesquisas sobre a COVID 19 que possa compreender e contextualizar outros aspectos, encaminhando estratégias nas políticas intersetoriais de minimização dos danos e vulnerabilidades associadas a vivência da pandemia e do isolamento social.

Assim, a pandemia COVID 19 é um acometimento de saúde da pública da população, em campos diversos, como na saúde mental, que não pode ser subestimado, ocasionando consequências profundas e necessidades de estratégias nas políticas publicas intersetoriais a curto, médio e longo prazo.

Portanto, Oliveira, Nobrega, Caetano e Soares (2020) afirmam que o tão procurado normal está agora figurado em como trataremos as mudanças; e que o trans e pós-pandemia exigirá ações de saúde mental individualizados e coletivos que atravessem a intersetorialidade, de produção de cuidados que possibilite ressignificação de rupturas no cotidiano da população.

É importante destacar que o sentido da linguagem dos colaboradores sobre o isolamento social na pandemia da COVID 19 possibilitou compreender fatores contextuais paralelos a transmissibilidade e acometimento do vírus, como especificidades sócio culturais regionais, particularidades da não adesão as medidas preventivas, consequências de saúde doença associando ao gênero, idade e condições sócioeconômicas, e suporte e apoio para toda a complexidade associada a vivência desta realidade.

\section{Considerações Finais}

Este estudo discorreu sobre a vivência de pessoas na pandemia da COVID 19 e o isolamento social, pretendendo conhecer esta vivência e desvelar os significados, por meio da análise hermenêutica da linguagem, dos contextos na experiência de processos pandêmicos e os efeitos nas emoções e processos da saúde mental.

A pluralidade dos significados sobre contextos socioeconômicos, as emoções provocadas e aprendizagens sobre a COVID 19 e as narrativas enfocadas em atos de fala voltados para o si mesmo e para o coletivo social, reforça a complexidade da vivência da pandemia e suas repercussões psicossociais, históricas, culturais, econômicas e políticas. Paralelo ao cenário da vivência do sujeito ainda se evidência realidade contemporânea do acesso tecnológico e o uso da informação, que neste contexto se fortaleceu, concretizado pela infodemia, com consequências devastadoras para a sociedade.

Compreende-se neste estudo que a vivências sobre as coisas do mundo da vida dos participantes encontra-se num imbróglio, na qual a insegurança de cada dia e suas experiências vividas mostram-se incisivo, ou seja, que produz uma sensação penetrante, forte, viva. Afinal, como seres sociais temos a necessidade de nos constituirmos na subjetividade pelas relações interpessoais, na troca de experiências e convivência, aspectos cada vez mais problemático no isolamento social e na pandemia da COVID 19.

Finalmente, com base a pluralidade dos significados advindos da pandemia na população é importante investirmos em estudos empíricos que contextualize este cenário, mas também os impactos sobre a complexidade sociocultural na saúde física e 
mental, adquirindo com isso, investir na integralidade das pessoas frente a contextos adversos de saúde e possibilitando ações estratégicas em políticas governamentais que priorize este enfoque.

\section{Agradecimentos}

Este estudo é parte do projeto de pesquisa expressão cotidiana e sofrimento psíquico na rotina originária da COVID 19, com recursos financeiros da chamada prospectivas de propostas de projetos e ações de pesquisa, inovação e extensão para o combate a COVID, do Comitê de Pesquisa, Inovação e Extensão de combate à COVID-19 da Universidade da Brasília (COPEI), Decanato de Pesquisa e Inovação/ Universidade de Brasília (DPI/UnB).

\section{Referências}

Crispim, D., Silva, M. J. P., Cedotti, W., Câmara, M. \& Gomes, S. A. (2020). Comunicação difícil e COVID 19: recomendação pratica para comunicação e acolhimento em diferentes cenários da pandemia. https://ammg.org.br/wp-content/uploads/comunica\%C3\%A7\%C3\%A3o-COVID-19.pdf.pdf

Guimarães, A. C. (2012). O Conceito de mundo da vida. Cadernos da EMARF, Fenomenologia $e$ Direito, 5(1), 29-45. https://sfjp.ifcs.ufrj.br/revista/downloads/o_conceito_de_mundo_da_vida.pdf

Guinancio, J. C et al. (2020). Covid - 19: desafios do cotidiano e estratégias de enfrentamento frente ao isolamento social. July 2020. Research Society and Development. 9(8):e259985474. 10.33448/rsd-v9i8.5474

Inter Agency Stadium Committee [IASC]. (2020). Guia Preliminar como lidar com os aspectos Psicossociais e de Saúde mental referente ao surto de COVID 19. https://interagencystandingcommittee.org/system/files/2020-03/IASC\%20Interim\%20Briefing\%20Note\%20 n $\% 20$ COVID-19\%20Outbreak\%20Readiness $\% 2$ 0and $\% 20$ Response $\% 20$ Operations $\% 20-\% 20$ MHPSS\%20\%28Portuguese $\% 29$.pdf

Lima, R. C. (2020). Distanciamento e isolamento sociais pela Covid-19 no Brasil: impactos na saúde mental. Physis: Revista de Saúde Coletiva, 30 (2), e300214. Epub July 24, 2020.https://dx.doi.org/10.1590/s0103-73312020300214

Madeiro, C. (2021). Covid: novo colapso em Manaus acende o alerta de que o pais pode repetir o caos. Viva bem. https://www.uol.com.br/vivabem/noticias/redacao/2021/01/08/covid-novo-colapso-em-manaus-acende-alerta-de-que-pais-pode-repetir-caos.htm

Medeiros, A. Y. B.V., Pereira, E. R., Silva, R. M. C. R. A. \& Dias, F.A. (2020). Fases psicológicas e sentido da vida em tempos de isolamento social por pandemia COVID-19 uma reflexão a luz de Viktor Frankl. Research, Society and Development, 9(5), e122953131. DOI: http://dx.doi.org/10.33448/rsd-v9i5.3131

Ministério da Saúde. (2020a). Painel de casos de doença pelo coronavínus 2019(COVID-19) no Brasil peloMinistério da Saúde.https://covid.saude.gov.br/

Organização Mundial da Saúde (2020). Coronavirus disease 2019 (COVID-19): Situation Report -51. https://www.who.int/docs/defaultsource/coronaviruse/situation-reports/20200311-sitrep-51-covid-19.pdf?sfvrsn=1ba62e57_10

Oliveira, D. S, Nóbrega, A. C. F, Caetano, G. N \& Soares, V. R. (2020). Por que todo dia é o mesmo no isolamento social? Quando ocupar não é preencher, mas ressignificar. Health residencies journal (HRJ), V.1 N.7. HTTPS://ESCSRESIDENCIAS.EMNUVENS.COM.BR/HRJ/ARTICLE/VIEW/100/74

Out, A., Charles, C. H. \& Yaya, S. (2020). Mental health and psychosocial well-being during the COVID 19 pandemic: the invisible elephant in the room. Int $J$ Ment Health Syst. 14:38 https://doi.org/10.1186/s13033-020-00371-w

OPAS. Organização Mundial da Saúde. Entendendo a infodemia e a desinformação na luta contra a COVID-19 - Folheto informativo - Mais informações sobre a COVID-19. https://iris.paho.org/bitstream/handle/10665.2/52054/Factsheet-Infodemic_por.pdf?sequence=14

Pereira, M. D., Oliveira, L. C., Costa, C. F. T., Bezerra, C. M. O., Pereira, M. D., Santos, C. K. A., \& Dantas, E. H. M. (2020). The COVID-19 pandemic, social isolation, consequences on mental health and coping strategies: an integrative review. Research, Society and Development, 9(7): 1-35, e652974548.

Pimentel, A. S. G \& Silva, M. N. R. M. (2020). Emoções a flor da pele: Riscos a saúde psíquica em tempos de Coronavirus. Em: Senhoras, E M (org). COVID-19: Saúde da Mente e do Corpo. Boa Vista: Editora da UFRR, 2020, 145 p.

Rosser E. N., Morgan R., Tan, H. et al. (2021). How to Create a GenderResponsive Pandemic Plan: Addressing the Secondary Effects of COVID-19. Gender and COVID-19 Project. https://www.genderandcovid-19.org.

Salles, M. M. \& Matsukura, T. S. (2015). Do indivíduo ao coletivo: perfil ocupacional de usuários de um Centro de Atenção Psicossocial. Revista de Terapia Ocupacional da universidade de São Paulo. Jan/Abr. 26 (1): 58 - 65. 2015. DOI10.11606.

Silva, M. N. R. M. O. (2019). Fazer acontecer no cotidiano: reconhecimento de si para encontro com outros. Em: Pimentel, A. \& Silva, M (orgs.). Diálogos Interdisciplinares em Saúde. UFPA/IFCHQ/PPGP/NUFEN.

Kaplan, J, Frias, L \& Johnsen, M. (2020). A third of the global population is on coronavirus lockdown - here`s our constantly updated list of countries and restrictions. Business Insider. 23, «A third of the global population is on coronavirus lockdown-here's our constantly updated list of countries and restrictions». 
Research, Society and Development, v. 10, n. 3, e59910314132, 2021

(CC BY 4.0) | ISSN 2525-3409 | DOI: http://dx.doi.org/10.33448/rsd-v10i3.14132

World Health Organization. Mental health and COVID-19. (2020). http://www.euro.who.int/en/healt h-topic s/healt h-emerg encie s/coron aviru s-covid-19/novel coron aviru s-2019-ncov-techn ical-guida nce/coron aviru s-disease-covid -19-outbr eak-techn ical-guida nce-europ e/menta 1-healt h-andcovid-19.

WHO. (2020). Rational use of personal protective equipment for coronavirus diease:interimguidance, WHO Feb, 27th, 2020- adaptado (morld mao covid, 2021. https://www.esri.com/pt-br/covid-19/community-maps/gallery\#/). https://storymaps.arcgis.com/stories/feaf86dac1584a84978a5e49d62266ca 